\title{
Article \\ Tidal Turbine Apparatus Vibration and Its Effect on Power Production Measurement
}

\author{
Yiyi Xu ${ }^{1,2}$, Jun Zhao ${ }^{1}$, Shuai Sun ${ }^{3}$ and Pengfei Liu ${ }^{4, *(1)}$ \\ 1 Guangxi University of Science and Technology, Liuzhou 545006, China; yiyi.xu@outlook.com (Y.X.); \\ jun.zhao.gust@outlook.com (J.Z.) \\ 2 Australian Maritime College, University of Tasmania, Locked Bag 1395, Launceston, TAS 7250, Australia \\ 3 National Key Laboratory of Transient Physics, Nanjing University of Science and Technology, \\ Nanjing 210023, China; shuai.s@njust.edu.cn \\ 4 Marine, Offshore and Subsea Technology, School of Engineering, Newcastle University, \\ Newcastle upon Tyne NE1 7RU, UK \\ * Correspondence: Pengfei.Liu@gmail.com
}

Citation: Xu, Y.; Zhao, J.; Sun, S.; Liu, P. Tidal Turbine Apparatus Vibration and Its Effect on Power Production Measurement. J. Mar. Sci. Eng. 2022, 10, 172. https://doi.org/10.3390/ jmse10020172

Academic Editor: Michael Hartnett

Received: 28 December 2021

Accepted: 24 January 2022

Published: 27 January 2022

Publisher's Note: MDPI stays neutral with regard to jurisdictional claims in published maps and institutional affiliations.

Copyright: (C) 2022 by the authors. Licensee MDPI, Basel, Switzerland. This article is an open access article distributed under the terms and conditions of the Creative Commons Attribution (CC BY) license (https:// creativecommons.org/licenses/by/ $4.0 /)$.

\begin{abstract}
The effect of vibration and oscillation of an instrumented testing apparatus on horizontal axis tidal turbine rotor energy generation performance was examined and analyzed. Enforcement struts and an accelerometer were installed to measure and record vibration during the test with and without struts. Three rotors with a solidity (i.e., expanded area ratio, EAR) of $0.25,0.4$, and 0.51 were tested to obtain the rotor energy generation performance data. The analysis of the results is focused on the rotor open-water performance, in terms of the drag and power coefficient, respectively. The results show the reduced overall oscillation/vibration achieved an improvement in the measured power coefficient of about $6 \%$ and the drag measurement improved by about $3 \%$. The allowable inflow velocity was also extended from 2 to $4 \mathrm{~m} / \mathrm{s}$. These results indicate that the enhanced vibration reduction method is effective and necessary for tidal turbine apparatus and its instrumentation.
\end{abstract}

Keywords: oscillation; propeller or turbine dynamometer; propeller and turbine rotor model testing; rotor testing apparatus; vibration

\section{Introduction}

There are many horizontal axis wind and current turbine rotor performance evaluation studies, in terms of both experimental measurements and full-scale trials. Typical examples on experimental lab-scale and full-scale studies include the study by Bahaj et al. [1], which produced a completed set of experimental testing data for a unidirectional-bladed tidal turbine rotor model with a controllable pitch, and Butterfield et al. [2] at the NERL, who contributed a set of measurement data from a full-scale trial of a wind turbine rotor. Even though many experimental tests have been recorded in the literature, current experimental data is inadequate due to the complexity of the turbine geometry and the combination operating condition of numerous variables. Experimental tests are still required to produce physical measurement data that can be used for numerical code validation and as a design reference. Increasingly more experimental studies are being presented to address the issue of a lack of measurement data. More examples of experimental research at the model scale include Liu et al. [3] and Alamian et al. [4].

Even though many turbine-rotor experimental studies exist in the literature, few research studies have addressed the accuracy and reliability issue of the testing apparatus due to the fast model speed at a high shaft revolution speed. To the authors' knowledge, the present study is the first attempt to improve the accuracy and reliability of data acquisition of fluid-structure-induced vibration of a turbine rotor model under a fast travelling speed and high shaft rotational speed. 
This experimental study was carried out based on a testing program conducted previously by Liu et al. [3]. In this program, an instrumented rotor testing apparatus was designed and built to measure the hydrodynamic performance of horizontal axis turbine rotors, and can be used for either propulsion testing via propellers or renewable energy performance measurement via tidal turbine rotors. A series of seven metal rotors and two plastic rotors were first tested using this testing apparatus. It was found in that testing program that the testing apparatus showed substantial vibration when the carriage speed was over $2 \mathrm{~m} / \mathrm{s}$ and hence it limited the inflow (carriage) speed beyond $2 \mathrm{~m} / \mathrm{s}$ [3].

Both the previous testing [3] and the testing of the current work were conducted at the Towing Tank at Australia Maritime College, University of Tasmania. To test the rotors, a testing apparatus, the so-called "opensboat" (Figure 1), was designed and built using a Kempf \& Remmers (K\&R) propeller dynamometer as the key load measuring unit. As the tidal turbine-measured torque on the rotor shaft is quite small, the smallest K\&R dynamometer available, R31 K\&R, was chosen. This dynamometer has a capacity of $4 \mathrm{Nm}$ torque and $100 \mathrm{~N}$ thrust or drag. Referring to bi-directional current turbine rotor testing [3], the same thrust capacity but a smaller torque capability of $2 \mathrm{Nm}$ is ideal for the experiment condition to fit the controller ampere rating, shaft speed, and carriage speed (inflow speed) of the towing tank.

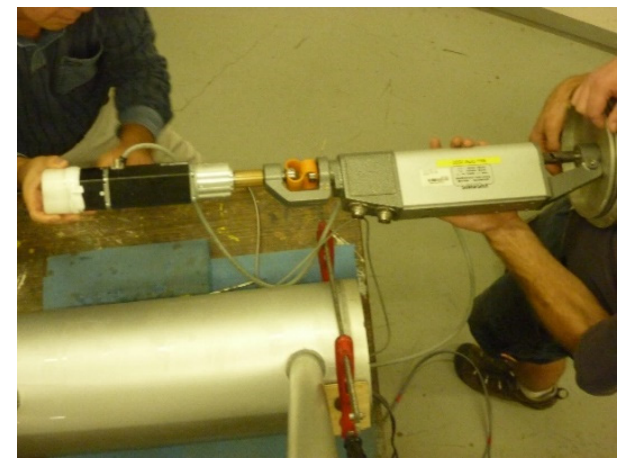

(a)

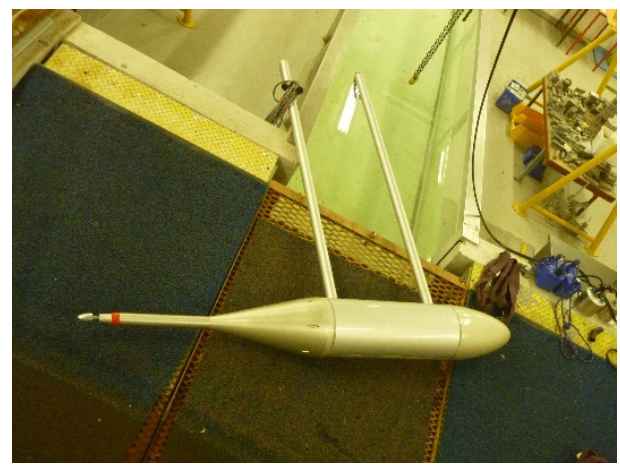

(b)

Figure 1. (a) Internal assembly and (b) opensboat external assembly.

Based on the previous bi-directional current turbine rotor testing program [3], the experiment on bidirectional turbine rotors in this study was conducted in an AMC towing tank. The rotors were designed and built for a dual-mode device that can be used either for propulsion or power generation. The internal assembly of the apparatus is shown in Figure 1a. In this assembly, a nylon seat (in white at the left end of the apparatus) is attached to provide a flatting mount to the torque and trust retainer, and the retainer is attached to the motor (the black part next to the while nylon seat), universal shaft coupling (the thin shaft part with pink joint), and a K\&R propeller dynamometer (the long part in at the right end. The completed assembly with only two cylindrical struts is shown in Figure $1 b$.

\section{Materials and Methods}

The AMC towing tank is the largest and only commercially operating facility of its type in Australasia with a $100 \mathrm{~m}$ long, $3.55 \mathrm{~m}$ wide, and $1.5 \mathrm{~m}$ deep water tank (Figure 2). A carriage was installed with a rail mechanism to tow structures at a maximum carriage speed of $4.6 \mathrm{~m} / \mathrm{s}$. It is used to measure the resistance of objects moving in water, such as ship hulls, submersibles, offshore oil rigs, and submarines. The AMC towing tank is also equipped with a metal beach to reduce wave reflection with a less than $5 \%$ reflection coefficient. Tow tank testing required operating condition [5] that met the reflection coefficient provided by Jamieson and Mansard [6]. 


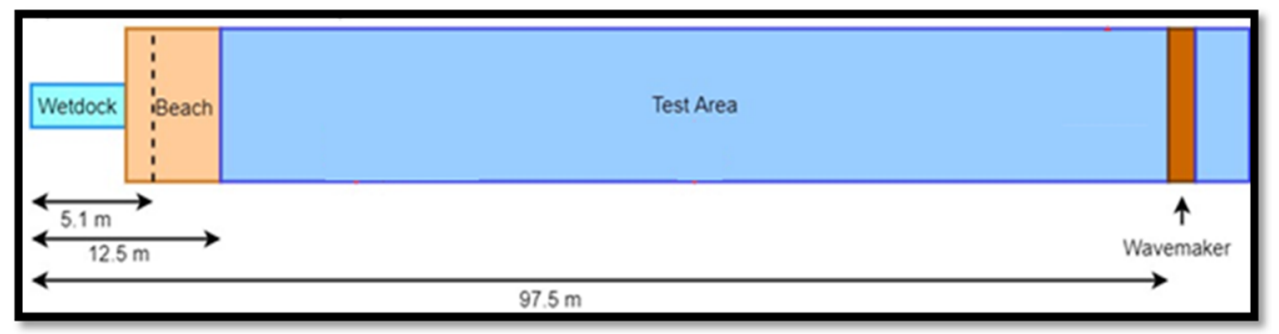

Figure 2. AMC towing tank layout.

It was discovered in the previous experimental work [3] that when using this apparatus, substantial vibration and transverse oscillation occurred when the carriage speed was more than $2 \mathrm{~m} / \mathrm{s}$. The carriage speed was initially set to $1 \mathrm{~m} / \mathrm{s}$ and no obvious vibration was noticed [3].

In this study, it was found that vibration consists of transverse oscillation of the apparatus body and vibration due to the fundamental frequency of the apparatus body.

To reduce the vibration and oscillation, we decided to strengthen the transverse strength of the apparatus body by adding strut support. The vibration recording was performed by using an accelerometer, which was installed in the opensboat body.

An accelerometer is a device that measures an object's proper acceleration. Proper acceleration [7] is the acceleration of a body in its own instantaneous rest frame, which is not the same as acceleration in a regular coordinate system. To measure vibration, a microelectromechanical system (MEMS) accelerometer was introduced (see Figure 3). To measure and analyze vibration, a vibration transducer was required. By measuring the displacement, velocity, acceleration, acoustic, magnetic, and optical properties of specific points, the vibration results can be measured with different types of sensors based on different operating principles.

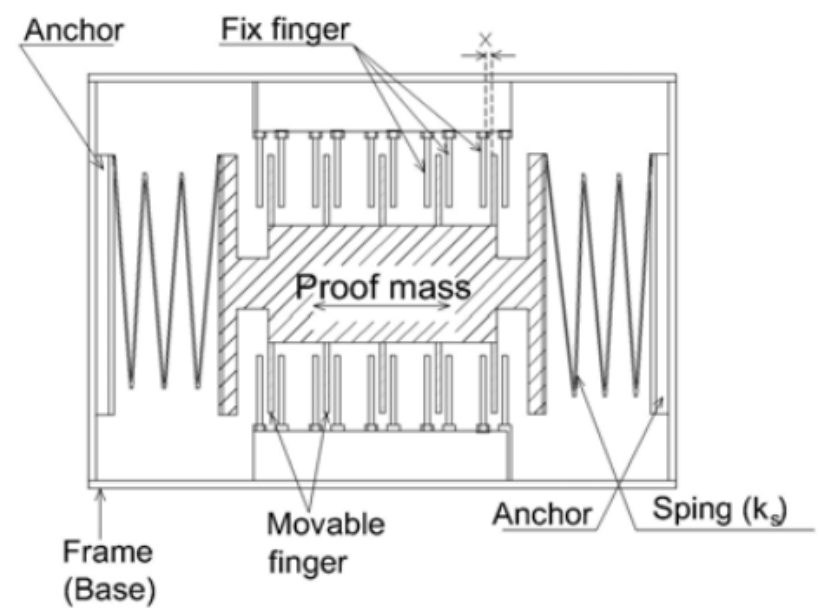

Figure 3. Sectional view of the MEMS accelerometer.

An MEMS accelerometer was operated based on the piezoelectric effect, which stresses a microscopic crystal using accelerative force and a capacitive operating principle, which changes the capacitance with microscopic seismic mass movement. The capacitive type is more widely used due to the minimal power required, excellent sensitivity, and large output signal.

This type of sensor works on the principle of capacitance variation between a set of sensing electrodes and reference (fixed) electrodes. The capacitance between two parallel plates is represented by ' $A$ ', as the area of each plate, and ' $d$ ', as the separation between the plates [8].

To verify the effect of vibration or opensboat body oscillation on open water rotor performance, as planned in this study, we assessed the improvement of the reduced 
vibration on the opensboat and hence the improvement in the measured tidal turbine rotor power generation performance along with the drag on the rotors, at various tip speed ratios. The instrumented opensboat was used to test the rotors of 3 different expanded area ratios (3 solidities), with or without strut support. A comparison of the effect of vibration reduction on the improvement of the hydrodynamic performance was conducted and the comparative performance (power and drag coefficients) was then presented. At the same time, an accelerometer was installed to record the vibration of the opensboat, as benchmark vibration data. A propeller dynamometer that has thrust and torque sensors was used to record the measured thrust and torque. The torque coefficient, thrust coefficient, and propeller efficiency were calculated first and converted to a power coefficient and drag coefficient based on the raw data captured and obtained from the K\&R dyno using the Texas Instrumentation Data Acquisition system and a dedicated desktop computer using an automated and Excel file programmed with macros. The conversion equations and procedure were taken from Liu and Bose [9]. The obtained hydrodynamic performance data were then evaluated and compared, and are presented in the next section.

\section{Results}

\subsection{Rotor Series}

For testing vibration, a series of model turbine rotors were designed and built for the "opensboat". Three-dimensional printed three-blade rotors with different blade area ratios (EAR) but the same pitch ratio and distribution and the same rotor diameter were tested using the opensboat. The material of the rotors printed by a 3D printer is ABS (Acrylonitrile Butadiene Styrene) plastic [10]. Acrylonitrile butadiene styrene is easy to fabricate and machine. Table 1 shows the properties of the rotor material. It is a low-cost engineering plastic that is suitable for structural applications due to its strength stiffness, impact resistance, and machinability. It is often used in food handling, oil and gas, aircraft, aerospace, and defense industries.

Table 1. ABS plastic properties.

\begin{tabular}{ccc}
\hline Property & Units & ABS \\
\hline Specific Gravity & & 1.04 \\
Flexural Modulus & $\mathrm{MPa}$ & 2344 \\
Flexural Strength @yield & $\mathrm{MPa}$ & 72 \\
Hardness-Rockwell & & $\mathrm{R} 105$ \\
Izod Impact Strength, Notched at $-40^{\circ} \mathrm{F}$ & $\mathrm{Kg}$ & 14.7 \\
Izod Impact Strength, Notched at $73^{\circ} \mathrm{F}$ & $\mathrm{Kg}$ & 42 \\
Tensile Modulus & $\mathrm{MPa}$ & 2137 \\
Tensile Strength at yield & $\mathrm{MPa}$ & 42 \\
\hline
\end{tabular}

These three rotors were all tested with or without struts. Figure 4 shows the three rotors that were made and tested in the testing program of this study.

The diameter of the rotors was $0.18 \mathrm{~m}$ with a varied expanded area ratio as indicted in the table. All other geometry properties, such as the pitch and pitch distribution, hubdiameter ratio, skew and skew distribution, rake and rake distribution, and blade sectional offsets, were the same as the rotors in Liu et al. [3], who described these properties in detail.

\subsection{Experiment Equipment and Apparatus}

The original design consists of a hollow bullet-shaped body with two hollow aluminum pipes that are connected to the moving carriage on the tow tank (Figure 5). In Figure 5, the opensboat assembly is shown (under water with the rotor outside the assembly). The opensboat is mounted on the tow tank carriage (i.e., the two-beam with webbing structure) via two structs (seen as two open tubes). The waterproof tubes also conduct the data and power/controller cables. 


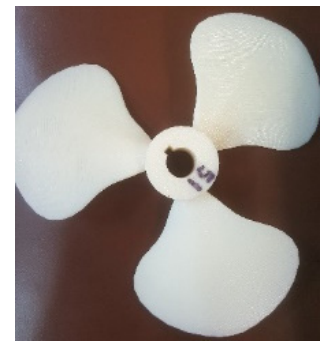

(a)

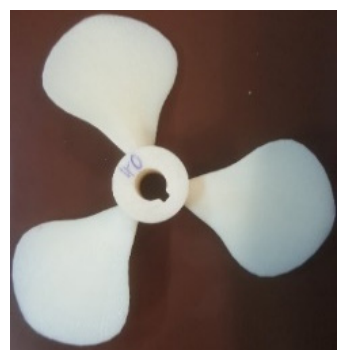

(b)

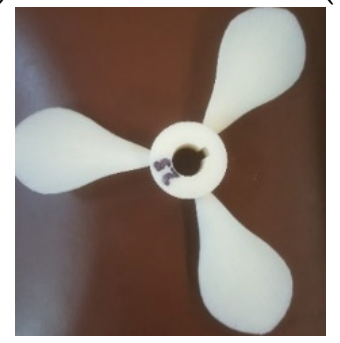

(c)

Figure 4. (a) 3D-printed 51\% solidity, (b) 3D-printed 40\% solidity, and (c) 25\% solidity.

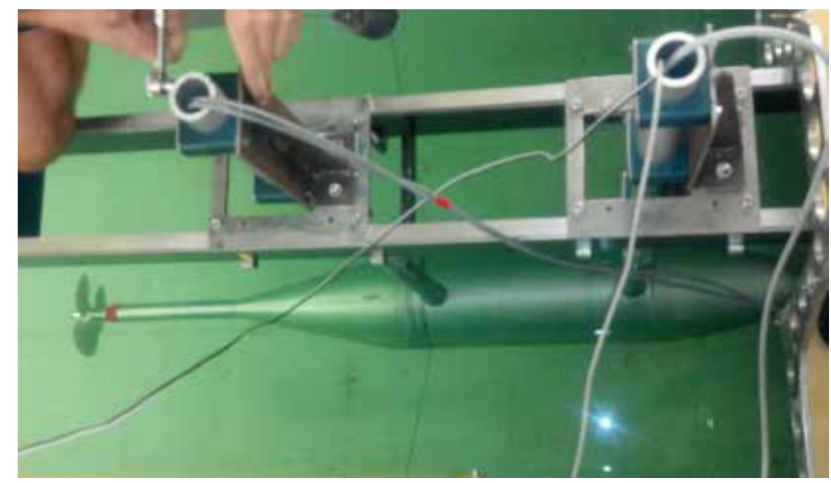

Figure 5. Original opensboat mechanism.

After a series of discussions and considerations, the opensboat was altered by wielding an aluminum plate with four brackets in between the hollow pipe to allow the opensboat to connect with another four metal struts with a ball joint in the carriage to prevent opensboat transverse oscillation while the rotor was being tested. An MEMS accelerometer Bruel \& Kjeer Type 4370 was installed in the interior wall of the opensboat body with industrial plasticine to capture the vibration of the opensboat as a benchmark to ensure the strut can provide enough stability while testing is in operation (Figure 6).

In Figure 6a, a thin tube is welded/added to each side of the opensboat shell. Two thin tubes (only one seen on each side) with one end being welded to the shell and the other end shown in Figure 6a is mounted on the carriage to strengthen the stability and rigidity in the sway direction. The total number of enforcement structs is four. Figure $6 \mathrm{~b}$ shows that a strengthening bracket is welded between the original struts to increase the stability and rigidity in the surge direction.

An BG 65 PI Motor, K\&R R31 propeller dynamometer, and flood sensor (Figure 7) were assembled and installed in the opensboat body. All the cables that carry signals were placed in the hollow pipes to the NI (National Instrumentation) signal filter and an amplifier to the computer. 


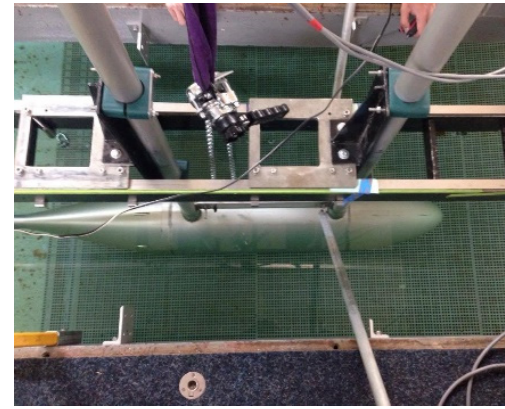

(a)

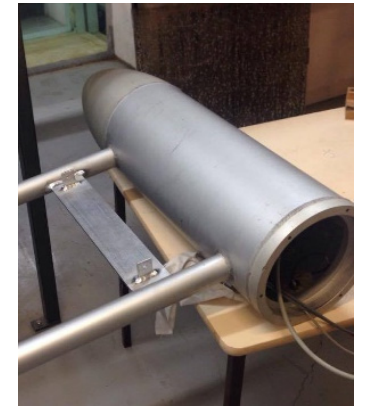

(b)

Figure 6. (a) Modified opensboat with 4 struts; (b) modified opensboat with bracket.

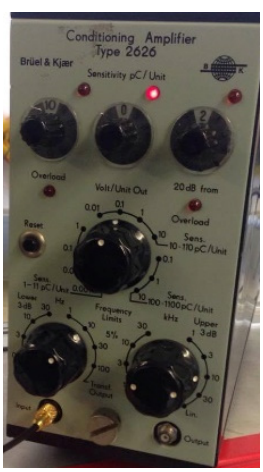

(a)

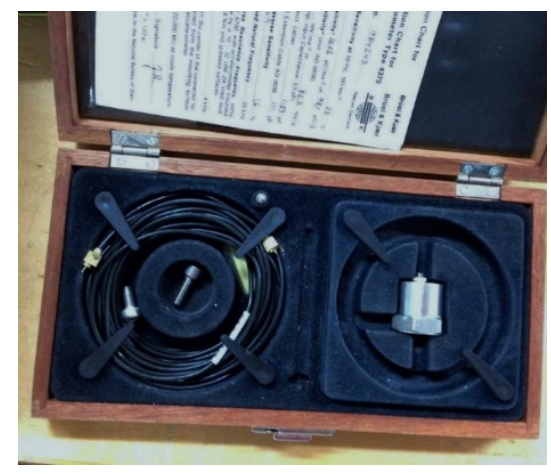

(b)

Figure 7. (a) Conditional Amplifier Type 2626; (b) Bruel \& Kjeer Type 4370.

The signal of the accelerometer is sent to an amplifier via a $3 \mathrm{~m}$ long cable. The accelerometer was then connected to the National Instrument (NI) filter to filtrate unnecessary noise and then to the computer (Figure 8a).

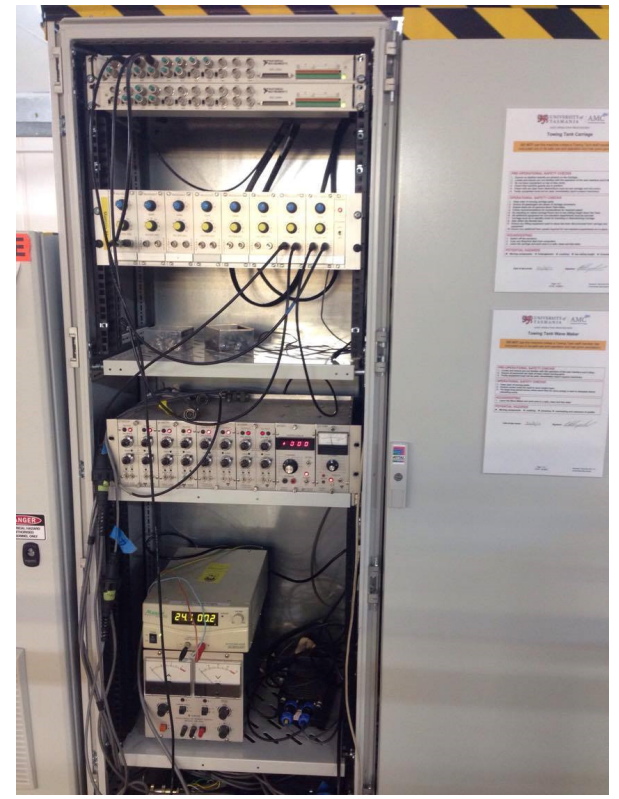

(a)

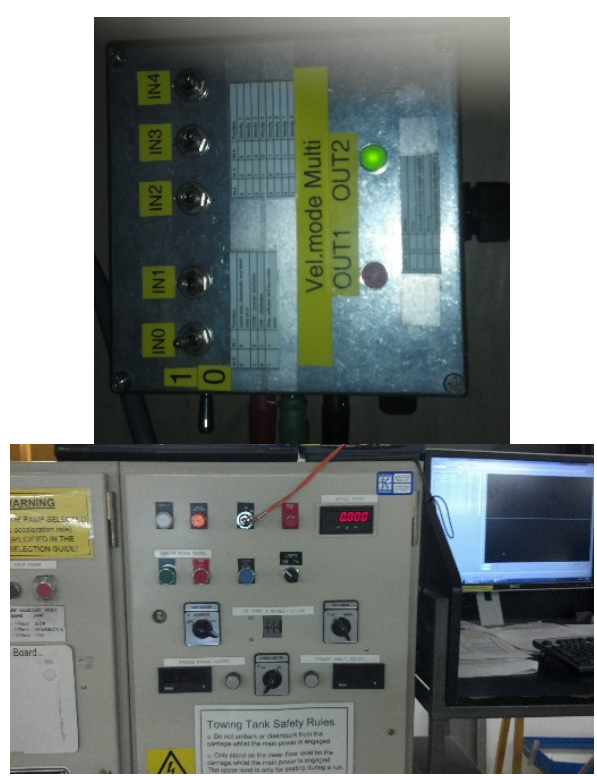

(b)

Figure 8. (a) Sensor filter, signal processing etc. (b) Binary box and master control panel for testing runs.

A binary box is installed to control the motor rotational speed. The motor has a gearbox ratio of 3:1 and the motor limit is $2500 \mathrm{rpm}$, so the maximum allowable rotor 
rotational speed is $833 \mathrm{rpm}$. However, at a much lower carriage speed, i.e., very slow inflow speeds, the motor can reach $3100 \mathrm{rpm}$ (Figure 8b). The control panel on the carriage for testing operation is also shown in Figure $8 \mathrm{~b}$.

Four clamps with an M6 bolt and nuts were installed to hold the two pipes of the opensboat on the carriage. A chain with a hook and sprocket with a metal bar were also used to jack the opensboat to an arm-reachable distance to allow rotor replacement during the test. The shaft was immersed at a depth of $0.75 \mathrm{~m}$, which is half of the towing tank depth, to reduce the free surface and bottom effect [3].

\subsection{Vibration Analysis}

As mentioned, during the previous testing, substantial transverse oscillation occurred in the opensboat when the carriage exceeded $1.5 \mathrm{~m} / \mathrm{s}$. This was verified in the current experiment.

The key data that need to be obtained in the current study is the observation and measurement that contains hydrodynamics and vibration. During the tank testing, data run 67 (with strut) and run 262 (without strut) for the same carriage speed of $2 \mathrm{~m} / \mathrm{s}$ and same motor rotational speed of $2105 \mathrm{rpm}$ were obtained, compared, and presented.

As the results show, the maximum vibration increased by $0.001 \mathrm{~mm} / \mathrm{s}^{2}$, and vibration also occurred more frequently after the strut was applied (comparing Figures 9 and 10), which means the struts worked effectively. At the same time, based on the observation, the oscillation of the opensboat body decreased to an unnoticeable level. This is because the struts resist the oscillation of the opensboat body in the transverse direction, and the body accelerates and decelerates in a shorter period (shorter oscillation period), which causes the accelerometer to capture higher acceleration, i.e., the increased resisting force with struts, not the magnitude of locational transformation.

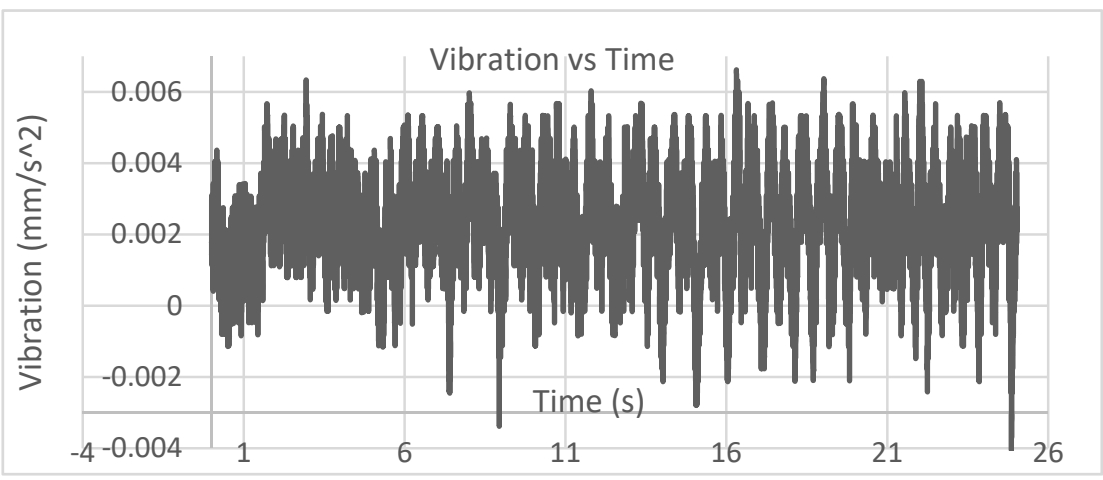

Figure 9. 025EAR without strut vibration vs. time (Run 067).

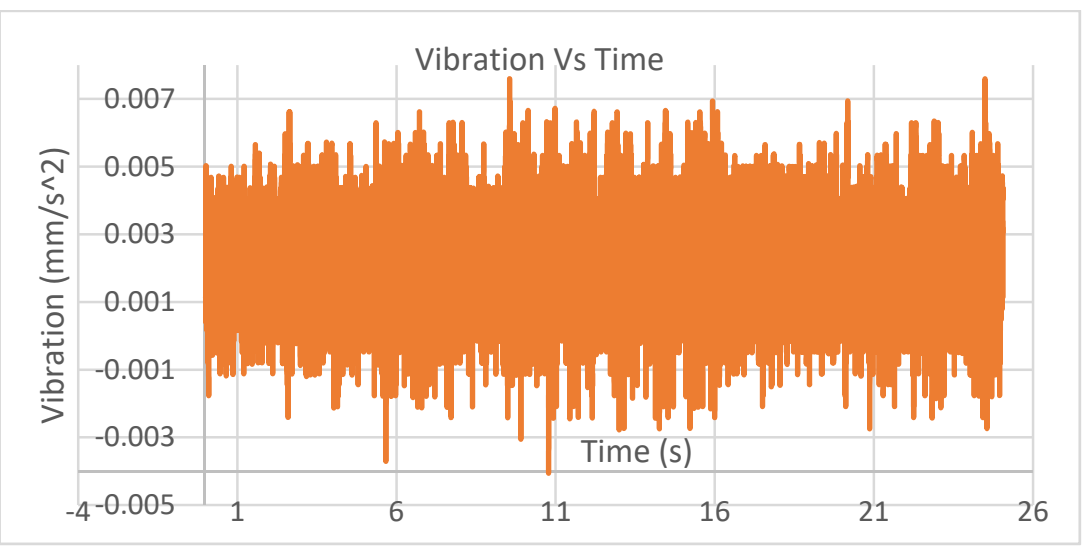

Figure 10. 025 with strut vibration vs. time (Run 262).

To identify the effect of vibration on the rotor, a graph of an open water propeller propulsion curve was plotted (Figures 11 and 12). The results of the $50 \%$ and $40 \%$ solidity 
rotors show no significant difference between the strut and no-strut conditions. This is because the testing of the rotors occurred under low carriage speed conditions. This indicates that reducing vibration for the propulsion test will not substantially improve the measured accuracy and performance when the carriage speed is very slow (less than $1 \mathrm{~m} / \mathrm{s}$ ) for the propulsion mode.

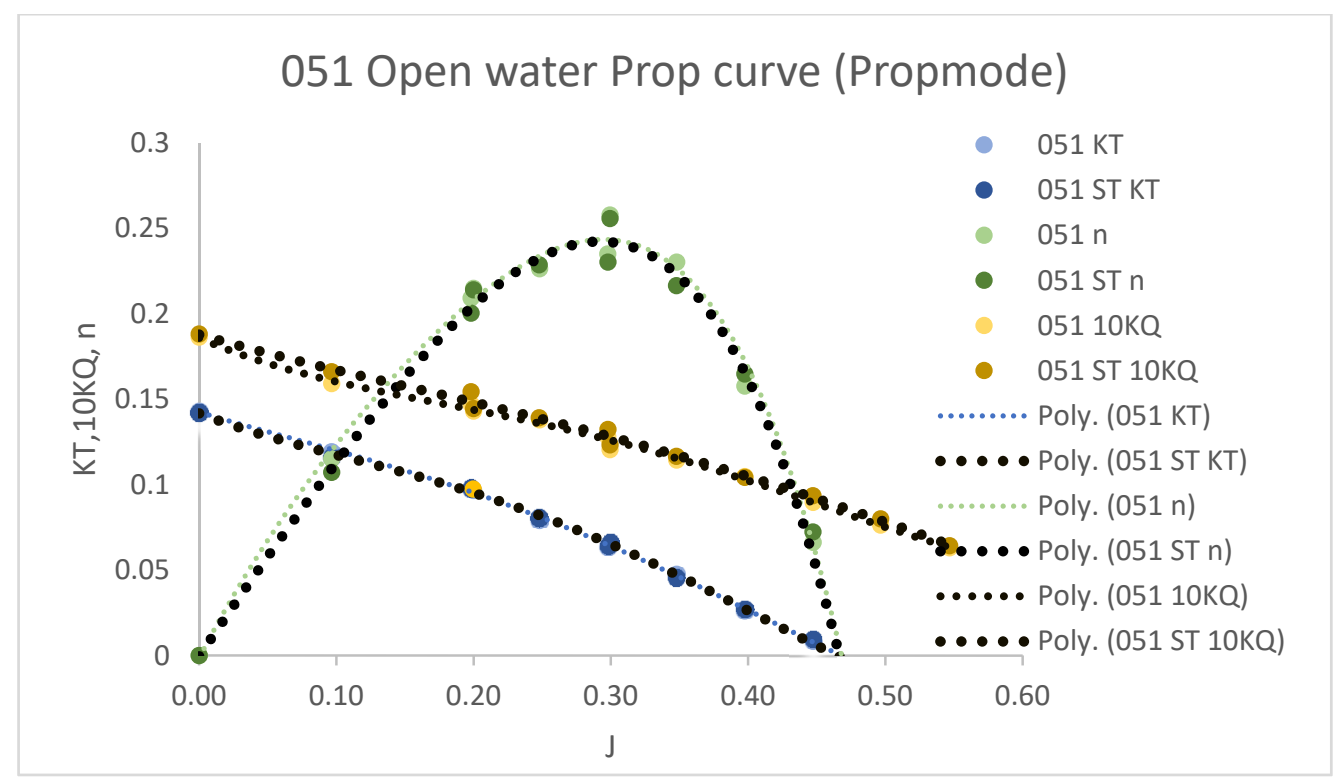

Figure 11. Open-water propeller performance curve.

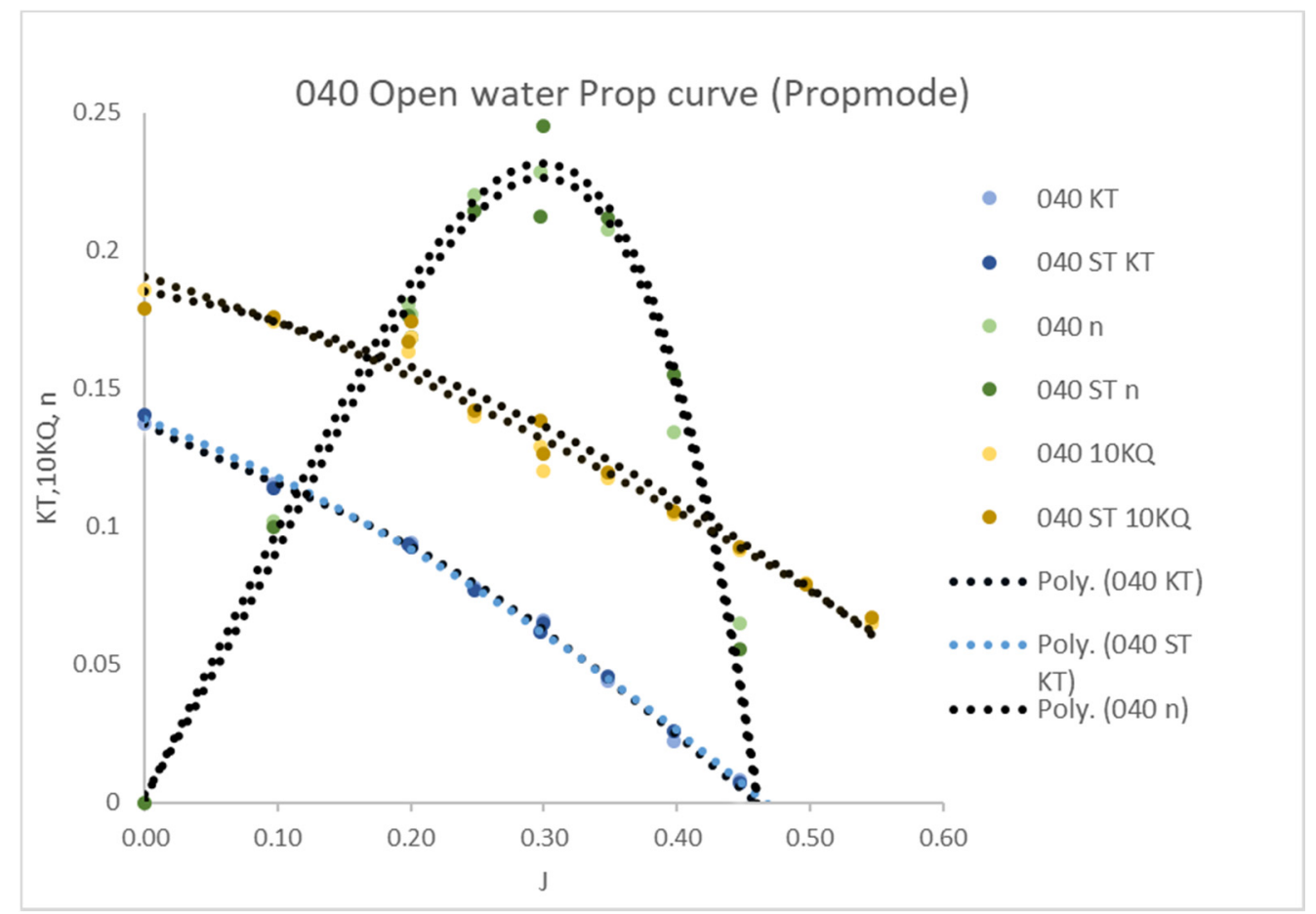

Figure 12. Open-water propeller performance curve.

3.4. Effect of Vibration on the Turbine Mode Power Coefficient with Various Pitch Ratios

Regarding the effect of the expanded area ratio on the power generation coefficient, the results of the rotor $25 \%, 40 \%$, and $51 \%$ solidities with and without struts are presented in Figure 13. 


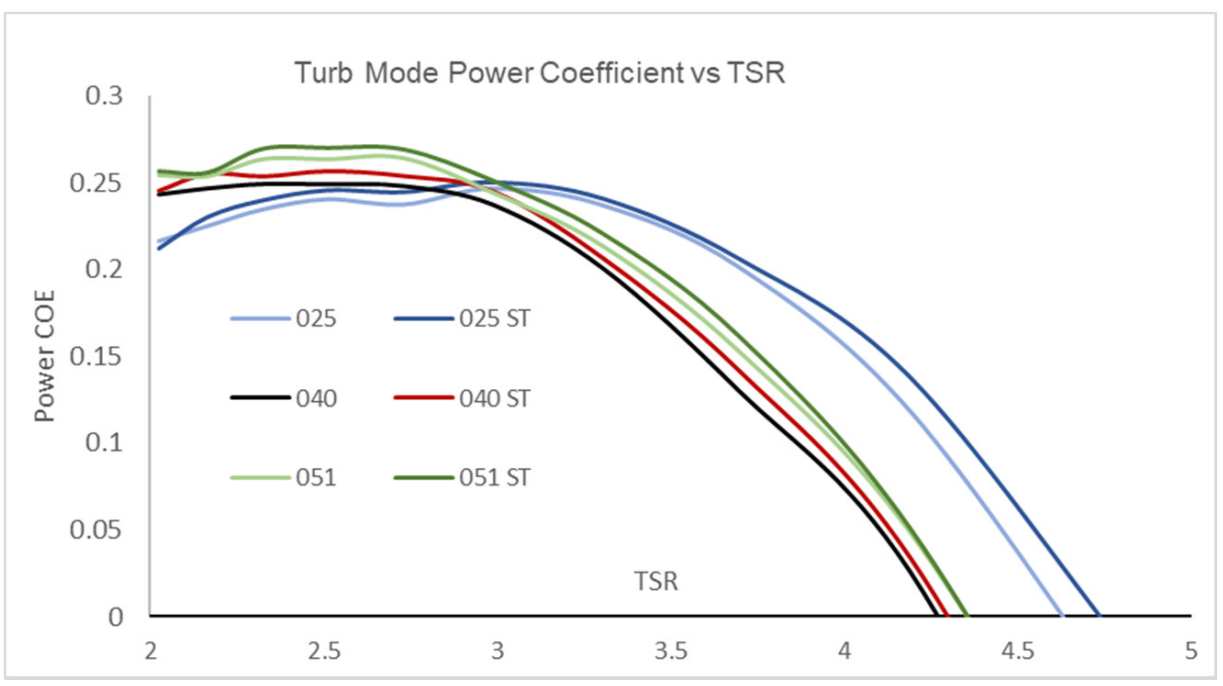

Figure 13. Power coefficient vs. TSR.

For the rotors with all solidities, the power coefficient increases to the highest point and starts to decrease at approximately 2.5 TSR. The largest solidity rotor $(\% 51)$ produced the highest power coefficient at an optimum tip speed ratio of about 2.5. All the rotors with struts produced a higher power coefficient due to the reduction of vibration and transverse oscillation. The improvement in power generation measurement for all the solidities (expanded area ratios) is substantial, for example, for the 025 and 040 rotors, the highest increase in the power coefficient is $56 \%$ and $31 \%$, respectively, at TSR $=0.418$, and for the 051 rotor, the power coefficient improvement is about $6 \%$ at TSR $=0.37$.

\subsection{Effect of Vibration on the Turbine Mode DRAG Coefficient with Various Solidities}

As commonly occurred, the drag coefficient decreases as the tip speed ratio increases because a higher tip speed ratio means a higher inflow speed (hence, a higher Reynolds number) and the drag coefficient is inversely proportional to the inflow speed (Reynolds number). It is as expected that the highest solidity generates the highest drag coefficient, i.e., the 051 rotor has the highest draft coefficient and the 025 rotor has the lowest because the higher the solidity, the higher the friction drag. A noticeable difference between the drag coefficients with struts or without struts can be seen in Figure 14. For all solidities, the drag coefficient measurement was improved by about $3 \%$ due to the reduction of vibration and transverse oscillation.

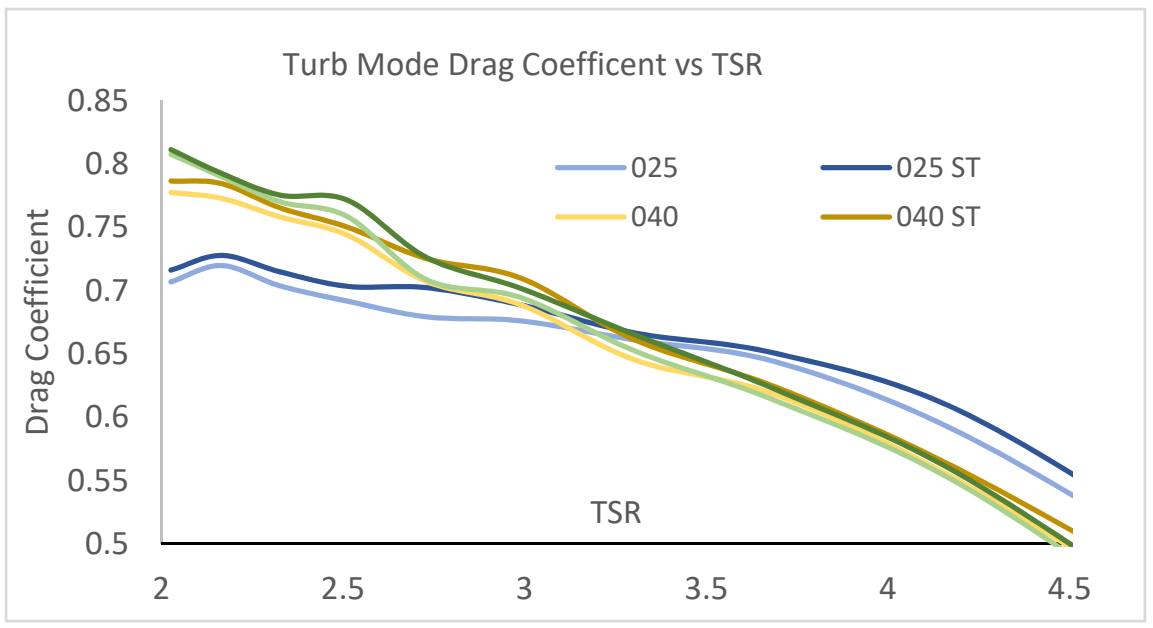

Figure 14. Drag coefficient vs. TSR. 


\subsection{Testing Procedure and Uncertainty Analysis}

Formal guidelines used for the turbine rotor testing procedure currently do not exist. However, the test program for this study was designed and conducted by following the ITTC propeller open-water testing and uncertainty analysis [11,12], and referencing the wind turbine testing work [13]. For typical propeller performance testing, the main procedure includes commission, testing, and decommission.

During testing, different rotors are switched at each constant carriage speed as the carriage speed is easier to change (by a dial) and the shaft rotational speed reaches the desired (prescribed) tip speed ratio TAR. The details of such typical propeller (turbine rotor) testing can be found in numerical publications in the literature. For details, see Liu et al. [3].

One of the most important requirements regarding achieving accurate and reliable data is to meet the Tare run requirement of the ITTC testing procedure. A tare run runs the test at a carriage speed of zero without a rotor on the shaft before the start of the data measurements each day to obtain a zero datum of the measurement. Without the tare testing, the resulting errors could be much larger than the uncertainty calculated by theory.

Uncertainty analysis was conducted by following the uncertain analysis guidelines of ITTC [12]. A list of the measurements and their ranges along with a sample calculation for a rotor with an expanded area ratio of 0.51 (i.e., solidity of 0.51 ) are given in Table 2 . In the table, the value of thrust is for the propeller, and it is drag for the turbine rotor.

Table 2. Measurements and precision for variables and sample uncertainty analysis for turbine drag results.

\begin{tabular}{|c|c|c|c|c|c|c|c|c|c|}
\hline Run & Time & Diameter D & $\mathrm{B}_{\mathrm{D}}(0.1 \%)$ & $\mathrm{dK}_{\mathrm{T}} / \mathrm{dD}=-4 \mathrm{~T}\left[\rho \mathrm{n}^{2} \mathrm{D}^{5}\right]$ & Motor Speed $n$ & $B_{n}(0.1 \%)$ & $\mathrm{d} K_{\mathrm{T}} / \mathrm{dn}=-2 \mathrm{~T}\left[\rho \mathrm{n}^{3} \mathrm{D}^{4}\right]$ & Thrust $\mathrm{T}$ & $\mathrm{B}_{\mathrm{T}}(2 \%)$ \\
\hline No. & $\mathrm{s}$ & $\mathrm{m}$ & [] & [] & Rps & [] & [] & $\mathrm{N}$ & [] \\
\hline 81 & 4.10 & 0.18 & 0.00018 & -2.008 & 19.11 & 0.19 & -0.0095 & 34.64 & 0.69 \\
\hline 82 & 4.16 & 0.18 & 0.00018 & -3.680 & 17.09 & 0.17 & -0.0194 & 50.80 & 1.02 \\
\hline 83 & 4.20 & 0.18 & 0.00018 & -6.136 & 14.82 & 0.15 & -0.0373 & 63.64 & 1.27 \\
\hline 84 & 4.24 & 0.18 & 0.00018 & -8.880 & 13.07 & 0.13 & -0.0611 & 71.69 & 1.43 \\
\hline 85 & 4.30 & 0.18 & 0.00018 & -12.201 & 11.69 & 0.12 & -0.0939 & 78.82 & 1.58 \\
\hline 86 & 4.33 & 0.18 & 0.00018 & -15.750 & 10.58 & 0.11 & -0.1339 & 83.34 & 1.67 \\
\hline Run & Timed & $\mathrm{T} / \mathrm{dT}=1 /\left[\rho \mathrm{n}^{2} \mathrm{D}^{4}\right]$ & Density $\rho$ & $\mathrm{B}_{\rho}(1 \%)$ & $\mathrm{dK}_{\mathrm{T}} / \mathrm{dT}=-\mathrm{T}\left[\rho^{2} \mathrm{n}^{2} \mathrm{D}^{4}\right]$ & {$\left[\mathrm{BK}_{\mathrm{T}}\right]^{2}$} & $\mathrm{~K}_{\mathrm{T}}=\mathrm{T} /\left[\rho \mathrm{n}^{2} \mathrm{D}^{5}\right]$ & $\mathrm{P}\left(\mathrm{K}_{\mathrm{T}}\right)^{2}$ & $\mathrm{U}_{\mathrm{KT}}$ \\
\hline No. & $\mathrm{s}$ & [] & $\mathrm{kg} / \mathrm{m}^{3}$ & [] & [] & [] & [] & [] & [] \\
\hline 81 & 4.1 & 0.0026 & 1000 & 10 & $-9.03 \times 10^{-5}$ & $7.48 \times 10^{-6}$ & 0.0903 & \multicolumn{2}{|c|}{$4.244 \times 10^{-7} 6.52 \times 10^{-4}$} \\
\hline 82 & 4.2 & 0.0033 & 1000 & 10 & $-1.66 \times 10^{-4}$ & $2.51 \times 10^{-5}$ & 0.1656 & \multicolumn{2}{|c|}{$5.305 \times 10^{-7} 7.29 \times 10^{-4}$} \\
\hline 83 & 4.2 & 0.0043 & 1000 & 10 & $-2.76 \times 10^{-4}$ & $6.98 \times 10^{-5}$ & 0.2761 & \multicolumn{2}{|c|}{$7.061 \times 10^{-7} 8.43 \times 10^{-4}$} \\
\hline 84 & 4.2 & 0.0056 & 1000 & 10 & $-4.00 \times 10^{-4}$ & $1.46 \times 10^{-4}$ & 0.3996 & \multicolumn{2}{|c|}{$9.072 \times 10^{-7} 9.64 \times 10^{-4}$} \\
\hline 85 & 4.3 & 0.0070 & 1000 & 10 & $-5.49 \times 10^{-4}$ & $2.76 \times 10^{-4}$ & 0.5490 & \multicolumn{2}{|c|}{$1.134 \times 10^{-6} 1.10 \times 10^{-3}$} \\
\hline 86 & 4.3 & 0.0085 & 1000 & 10 & $-7.09 \times 10^{-4}$ & $4.60 \times 10^{-4}$ & 0.7088 & \multicolumn{2}{|c|}{$1.384 \times 10^{-6} 1.26 \times 10^{-3}$} \\
\hline
\end{tabular}

This test was designed and conducted with a tank carriage speed of 1.5, 2.0, 2.5, and $3.0 \mathrm{~m} / \mathrm{s}$. The revolution speed of the motor was reduced using a 3:1 gear box. An average run elapsed time of $4 \mathrm{~s}$ was set for each data point. The sample rate was taken at $3.156 \mathrm{kHz}$, so the number of measurements for each data point was about 12,530. The standard deviation using the raw data was calculated (SDev (thrust) $=2.039061)$ and converted to $\mathrm{K}_{\mathrm{T}}$. The maximum uncertainty $\mathrm{U}_{\mathrm{KT}}$ among all the TSRs (tip speeds) was found to be only 0.00126 .

\section{Conclusions}

To improve the instrumented turbine rotor measuring apparatus for better reliability and accuracy, a reduction of the vibration and transverse oscillation was implemented by using four strengthening struts and a set of brackets. The improvement was obtained by analyzing and comparing the hydrodynamic characteristics of three turbine rotors of different solidities. The vibration of the apparatus in operation during the tests was also measured and recorded. 
An uncertainty analysis was conducted using the procedure and guideline of ITTC's propeller open water testing uncertainty analysis documentation. A sample calculation of the rotor drag at various tip speed ratios (TSRs) was completed for the EAR $=0.51$ rotor with a test run number 180 . The maximum uncertainty $\mathrm{U}_{\mathrm{KT}}$ among all the TSR was found to be only $0.005 \%$, which indicates sound reliability and accuracy of the data obtained.

The results show that due to the reduction of vibration and transverse oscillation, the reliability and accuracy of the measurements was improved substantially. The maximum improvement of the power coefficient measurement was about $56 \%$ at TSR $=4.18,31 \%$ at $\mathrm{TSR}=4.18$, and $6 \%$ at TSR $=3.7$, respectively, for rotors with a corresponding solidity of $0.25,0.40$, and 0.51 . Substantial improvement in the measurement of the drag coefficients for these rotors was also obtained at about $3 \%$.

Author Contributions: Conceptualization, P.L. and Y.X.; methodology, Y.X. and P.L.; validation, Y.X. and J.Z.; formal analysis, Y.X., S.S. and P.L.; resources, P.L.; writing-original draft preparation, Y.X. and S.S.; writing-review and editing, P.L. and J.Z.; project administration, P.L. and J.Z.; funding acquisition, Y.X., J.Z., P.L. All authors have read and agreed to the published version of the manuscript.

Funding: Research Training Program (RTP) Stipend (Tasmania Graduate Research Scholarship (TGRS)), School of Engineering at Newcastle University (OSR/0561/SASC/0017), Royal SocietyNSFC International Exchanges Grant (IEC \NSFC $\backslash 201152$ ), National Natural Science Foundation of China (NSFC 51568008).

Informed Consent Statement: Not applicable.

Data Availability Statement: Available upon request.

Acknowledgments: The authors thank to their affiliations for support. This work was supported in part by Research Training Program (RTP) Stipend (Tasmania Graduate Research Scholarship (TGRS)) for PhD candidates at Australian Maritime College, University of Tasmania, School of Engineering at Newcastle University (OSR/0561/SASC/0017), Royal Society-NSFC International Exchanges Grant (IEC $\backslash N S F C \backslash 201152$ ) and the National Natural Science Foundation of China (NSFC 51568008). Thanks to Zishen Ng and AMC Tow Tank facility staff who helped with the testing and data acquisition.

Conflicts of Interest: The authors declare no conflict of interest.

\section{Nomenclature}

$\begin{array}{lll}\text { Notation } & \text { Description } & \text { Unit } \\ \mathrm{A} & \text { Rotor swept area } & \mathrm{m}^{2} \\ \mathrm{R} & \text { Propeller/rotor radius } & \mathrm{m} \\ \mathrm{J} & \text { Advance ratio } & {[]} \\ \mathrm{N} & \text { Motor shaft speed } & \mathrm{rps} \\ \mathrm{D} & \text { Rotor diameter } & \mathrm{m} \\ \mathrm{EAR} & \text { Expanded area ratio/solidity } & {[]} \\ \mathrm{TSR} & \text { Tip speed ratio } & {[]} \\ \Omega & \text { Shaft rotational speed } & \mathrm{rad} / \mathrm{s} \\ \mathrm{V} & \text { Carriage speed/inflow speed } & \mathrm{m} / \mathrm{s} \\ \mathrm{Cpow} & \text { Power coefficient } & {[]} \\ \mathrm{Q} & \text { Torque } & \mathrm{Nm} \\ \rho & \text { Fluid density } & \mathrm{kg} / \mathrm{m}^{3} \\ \mathrm{Ct} & \text { Drag coefficient } & {[]} \\ \mathrm{T} & \text { Thrust } & \mathrm{N} \\ \mathrm{Kt} & \text { Thrust coefficient } & {[]} \\ \mathrm{Kq} & \text { Torque coefficient } & {[]} \\ \eta & \text { Propeller open water efficiency } & {[]}\end{array}$




\section{References}

1. Bahaj, A.S.; Molland, A.F.; Chaplin, J.R.; Batten, W.M.J. Power and thrust measurements of marine current turbines under various hydrodynamic flow conditions in a cavitation tunnel and a towing tank. Renew. Energy 2007, 32, 407-426. [CrossRef]

2. Butterfield, C.P.; Musial, W.P.; Simms, D.A. Combined Experiment Phase 1. Final report (No. NREL/TP-257-4655); National Renewable Energy Lab.: Golden, CO, USA, 1992.

3. Liu, P.; Bose, N.; Frost, R.; Macfarlane, G.; Lilienthal, T.; Penesis, I.; Windsor, F.; Thomas, G. Model testing of a series of bi-directional tidal turbine rotors. Energy 2014, 67, 397-410. [CrossRef]

4. Alamian, R.; Shafaghat, R.; Amiri, H.A.; Shadloo, M.S. Experimental assessment of a $100 \mathrm{~W}$ prototype horizontal axis tidal turbine by towing tank tests. Renew. Energy 2020, 155, 172-180. [CrossRef]

5. $\quad \mathrm{Ng}$, Z.S.; Lim, J.W. AMC Towing Tank Beach Wave Reflection; Student Report; Australian Maritime College, University of Tasmania: Tasmania, Australia, 2017.

6. Jamieson, W.W.; Mansard, E.P. An efficient upright wave absorber. In Coastal Hydrodynamics; ASCE: Reston, VA, USA, 1987; pp. 124-139.

7. Rindler, W. Accelerometer MEMS. Essential Relativity: Special, General, and Cosmological (illustrated ed.); Springer: New York, NY, USA, 2013; p. 61. ISBN 978-1-4757-1135-6.

8. Chaudhury, S.B.; Sengupta, M.; Mukherjee, K. Vibration monitoring of rotating machines using MEMS accelerometer. Int. J. Sci. Eng. Res. 2014, 2, 5-11.

9. Liu, P.; Bose, N. Prototyping a series of bi-directional horizontal axis tidal turbines for optimum energy conversion. Appl. Energy 2012, 99, 50-66. [CrossRef]

10. Plastic International. ABS Plastic. Available online: http://www.plasticsintl.com/abs.htm (accessed on 27 December 2021).

11. ITTC. Testing and Extrapolation Methods: Propulsion, Performance Propulsion Test; ITTC Tech. Rep. 7.5-02-03-01.1.; 2002; 9p.

12. ITTC. 2014, Uncertainty Analysis, Example for Open Water Test; Revision 1; 2014; 15p.

13. Ashwill, T.D. Measured Data for the Sandia 34-Meter Vertical Axis Wind Turbine; Sandia National Laboratories: Albuquerque, NM, USA, 1992 